\title{
New perspective of nanotechnology: role in preventive forensic
}

\author{
Alok Pandya ${ }^{1}$ and Ritesh K Shukla ${ }^{2^{*}}$
}

\begin{abstract}
Background: Generally, material scientist discussing new-fangled nanotechnology research and its conversation turns to the commercial aspects or potential issues around health, safety, and the environment. In recent years, few of them have been shown interest to apply nanotechnology for forensic purposes which are related to societal or community issues.

Main text: In forensic science, nanotechnology majorly is applied to develop reactive ('smart') materials; microchip technology; nanomanipulators; nanoimaging tools for visualization. These advances in forensic technologies have mainly been focused on analytical techniques. These techniques are based on nanomaterials that are able to provide either improved performance over conventional techniques or enable to collect information from a crime scene that would not otherwise have been possible ever. Moreover, some crucial forensic issues such as cost and time effectiveness, wide availability, accuracy, and reliability of results are major concerns in forensic investigation and security.

Conclusion: With the help of this review article, an attempt was made to elucidate how nanotechnologies could be crucial in addressing current forensic investigation issues such as collection and analysis of evidence from the crime scene and how these technologies may be helpful in preventive forensic and security measures.
\end{abstract}

Keywords: Nanotechnology, Preventive forensic, Forensic investigation

\section{Background}

Nanotechnology is a combination of various field of physical, chemical, and biological sciences that study the phenomenon on the nanometer scale $(1 \mathrm{~nm}-1$ billionth of a meter) (Pitkethly 2010). A couple of years ago, nanotechnology have been part of science fiction novels and subject of speculative researches in clandestine laboratories. Nowadays, nanotechnology is one of the most promising but disputable emerging technology among the existed technologies (Teeuw et al. 2008).The research in forensic science perceived as the process of using specific techniques and methods for inspecting, gathering, and analyzing trace evidences at the scene of crime. Nowadays, introduction of nanotechnologies in forensic science will significantly transform the processes of investigation by making them faster, more accurate, more effective, more sensitive, and easy to apply that explains the indisputable

\footnotetext{
* Correspondence: ritesh.shukla@ahduni.edu.in

${ }^{2}$ Biological and Life Sciences, School of Arts and Sciences, Ahmedabad

University, Central Campus, Navrangpura, Ahmedabad 380009, Gujarat, India Full list of author information is available at the end of the article
}

significance of this technologies (Lodha et al. 2016). Few research groups have focused on nanotechnology which is applied in the field of forensic science such as reactive ('smart') materials, microchip technology, nanomanipulators, nanoimaging tools for visualization (McCord 2006).

In this continuance, nanoplatform alone or in junction with other technologies is expected to have significant application in security, drug screening, explosive detection, and DNA analysis which enable forensic investigators to perform complex analysis or to discover even the smallest traces of evidence at the crime scene (Chen 2011). However, application and improvement implications should also be analyzed in order to draw the full picture of possible application of nanomaterials in forensic science, so that no chance of risk or uncertainty is left behind unexplored (Shukla 2013).

Furthermore, two additional very specific nanotechnology applications have also been widely discussed in the previous literatures, namely, nano sprayers and "lab-on-a-chip" device. Nano sprayers used to find even the 
smallest trace evidence on the crime scene and the lab-on-a-chip device is capable to perform multiple analysis and tests using incredibly small quantity of sample (Giannoukos et al. 2016). Development of advanced trace evidence collection and analysis tools will be highly needed due to the fact that materials would have become almost immaculate and thus harder to detect and identify. In that respect trace evidences themselves are expected to become smaller, even to the amount of a single cell. With the help of nanotechnology detection and analysis of a single DNA molecule in forensic research would be possible (Saiyed et al. 2008; Foquet et al. 2002).

In addition, the new analytical devices would replace the existing chemical labs with multiple hand held devices and processes. It may able to perform complex chemical and biological analysis precisely on the spot of crime scene that would reduce the time needed to proceedings. Lab-on-a-chip devices are easy to perform, and no special training required to use these devices which makes interpretation even more easy, rapid, and accurate than the current lab results (Mark et al. 2010). The abovementioned technologies are expected to become available for the general public, which can be very beneficial for the involvement of the broader circle of participants in the forensic research and in the general crime prevention. Moreover, described nanotechnology can not only serve as forensic tool itself, but also actually enable further functions to be developed (e.g., smart designed devices), so that a synergy in the convergence of technology to be witnessed. Another important advantage of nanotechnology in forensics discussed in the literatures is the integration of existing laboratory processes into single device that would be able to handle laboratory contamination problems (Lad et al. 2016). All such nanotools are playing an important role considering their well-known advantages of sensitivity and selectivity. It is due to appropriate selection of molecular receptors of a nanosensor which serve as templates for the material to be detected.

To enhance the security and to prevent the crime, nanotechnology has proved its efficiency. Security issues included protection of citizen, prevention from fraud, prevention measures against organized crime and terrorism (Docobo 2005). In many countries, futile methods used for crime prevention are the major issue of high rate of crime. Basically, the methods which have been used to prevent and detect crime are not very specific/ effective, that is why it stuck law enforcement officers from preventing/investigating crime (Gordon 2011). When law enforcement officers are unable to carry out proper forensic investigation, it may affect the security measure.

In addition, analysis of forensic evidences is ensuring that whether suspect is criminal or innocent. In most of the cases, due to trace amount of forensic material, analysis would be difficult and therefore, it is hard to ensure the link between crimes with suspect. Finally, either case is in pending stage or unsolved. To resolve this issue, nanotechnologies play a crucial role in addressing current security apprehensions. For example, nanotechnology-based method immensely improves the collection and analysis process of physical evidences found at the scene of crime which may not only help to transform the crime investigation process but also to the judiciary system (Fourth Nanoforum Report 2004). These revolutionary changes in forensic technology will continue to renovate forensic investigation and judiciary system along with the development of more tools for crime prevention. Therefore, this review article emphasized to elucidate the crucial role of nanotechnology in addressing current forensic investigation issues such as collection and analysis of evidence from the crime scene that could be helpful in crime prevention and security measures (Fig. 1).

\section{Main text \\ Role of nanotechnology in forensic investigation Fingerprint identification}

Since ancient time, fingerprints have been used as unique evidences which were later also used on Babylonian clay tablets for business transaction (Pitkethly 2010). Ideally, the fingerprint powder will fix to the residues left by the finger and give rise to the distinctive patterns that help to identify an individual as a fingerprint, but not stick to background or other surface. Latent fingerprints are commonly developed by various colored materials such as carbon black on white/light background and aluminum flake on black/dark background. The drawback of these materials is its adherence power because they do not only help to decipher the latent fingerprint but also stick to the background of the fingerprint. Since they adhere to both print and its background, it is difficult to get clear image of the fingerprint, so identification is a major issue. In this condition, engineered or synthesized nanoparticles are being used to overcome this problem. In forensic science, nanotechnology can be helpful in collection and analysis of the evidences found at the crime scene. Forensic experts gather extensive range of physical evidences from the scene of crime that would be helpful to correlate a suspect with the crime. These physical evidences not only link an individual/group of individuals with crime but also help to prove them innocent. In the normal procedure, after collecting the evidences, they are packed appropriately and sent to the laboratory for further analysis. These procedures are time-consuming and chances of error are more. In addition, a study revealed that micro X-ray fluorescence method can be used to visualize the latent fingerprint (Worley et al. 2006). In this effective method, latent 


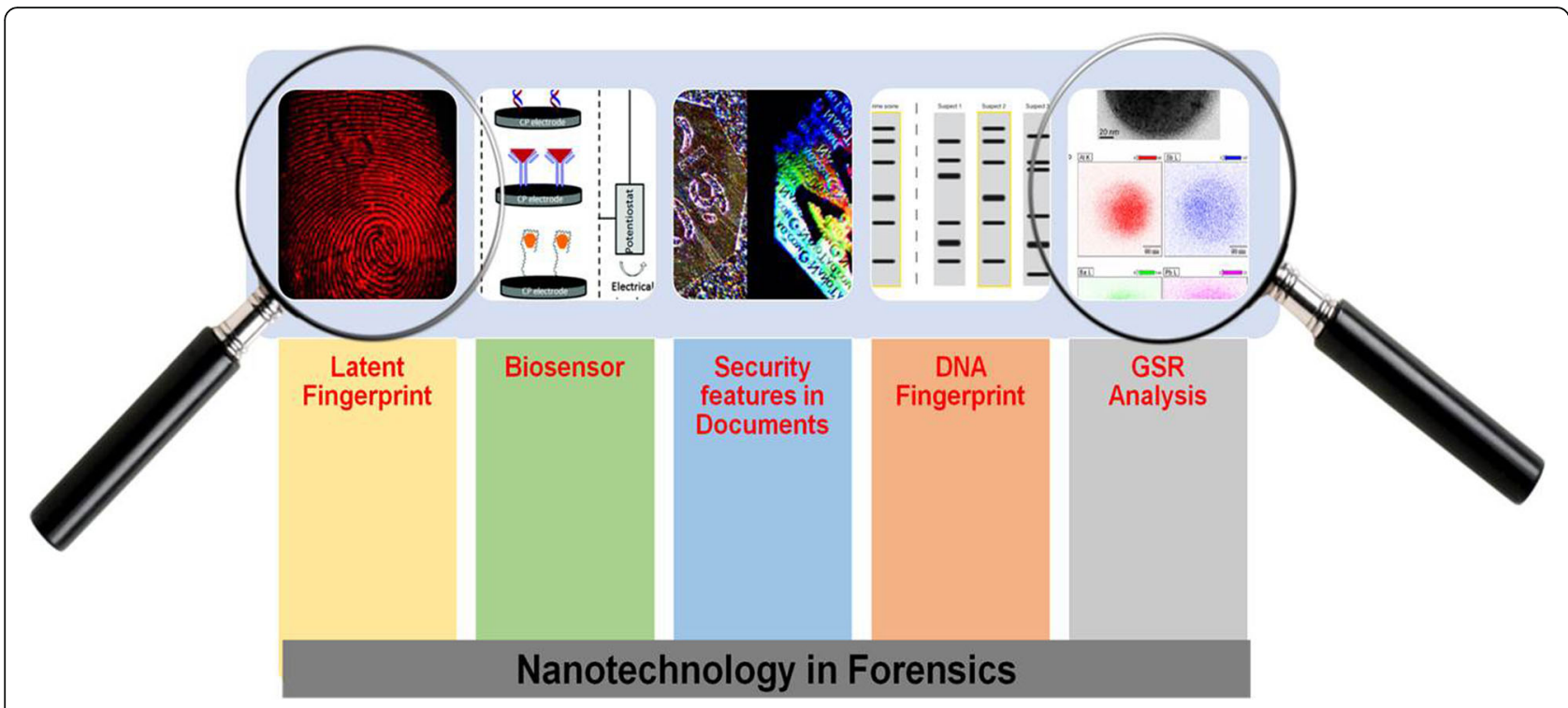

Fig. 1 Role of nanotechnology in forensic

fingerprint becomes visualized by ascertaining inorganic constituents that are present in the prints. This method is in contrast to the chemical enhancement methods that have been applied to visualize latent fingerprints. This micro X-ray fluorescence method has several advantages over conventional chemical method for detecting latent finger prints. Micro X-ray fluorescence is a non-destructive method that does not affect the analysis and the stability of the inorganic residues during image formation of fingerprints. During analysis of the fingerprint, result revealed that some of the residues contain silicon, aluminum, and calcium ( $\mathrm{Su} 2016$ ). Still this method required instrument and trainer to conduct such analysis. However, latest nanotechnologybased techniques can help to analyze the evidences on the spot at the scene of crime; that not only save the time of analysis but also reduce the chances of error. Nowadays, in the forensic investigation process, different types of nanopowders have been applied to reveal the latent fingerprints on various surfaces (Torgal and Jalali 2011). In this order, photoluminescent CdS semiconductor nanocrystals capped with dioctysulfo-succinate had been used to improve the detection of fingerprints (Menzel 2001). Recently, a group of researchers (Arshad et al. 2015) have synthesized novel $\mathrm{ZnO}-\mathrm{SiO}_{2}$ nanopowder using the conventional heating method. The fingerprints were developed by powder dusting and small particle reagent (SPR) methods. This method has been effectively applied on various dry (semi-porous and non-porous) and wet (non-porous) surfaces to visualize the latent fingerprints as shown in Fig. 2. The results exhibited that $\mathrm{ZnO}-\mathrm{SiO}_{2}$ nanopowder has excellent potential to envisage finger ridge detail at higher-level that shows superior discernibility than other commercially available white powders.

\section{Explosive residue detection}

Today, terrorism is the biggest societal enemy worldwide. Its enormous growth is because of simple manufacturing of explosive-based weapons/devices; it is easy to deploy, and their consequence as a massive destruction (Colton 2003). Detection of trace amounts of explosive is a challenging task because of number of issues, such as low quantity of unexploded explosives, contaminated samples, and different sample collection procedure. In the case of bomb blast, fragmented residues of explosive can be scattered from the actual place of blast while unfragmented part of explosive remain at the scene of the crime. During the crime scene investigation, investigators can use nano-based technology to identify the unfragmented/trace amount of fragmented explosives from the crime scene. In most cases of bomb blast, it is difficult for an investigator to identify unfragmented explosives. Hence, the investigators are unable to provide enough evidence to corroborate the link between the accused and the crime scene in the court, which is further not adequate for conviction (Kosal 2008). Here, nano-based technology can be useful to analyze untraceable explosive cases. With the help of nano-based technology, investigators are capable to detect microscopic particles of gun powders on the shooter's hand (Mosher et al. 1998). In addition, due to usage of futile method for detection of gunshot residue, investigators are unable to identify even single particles of the 


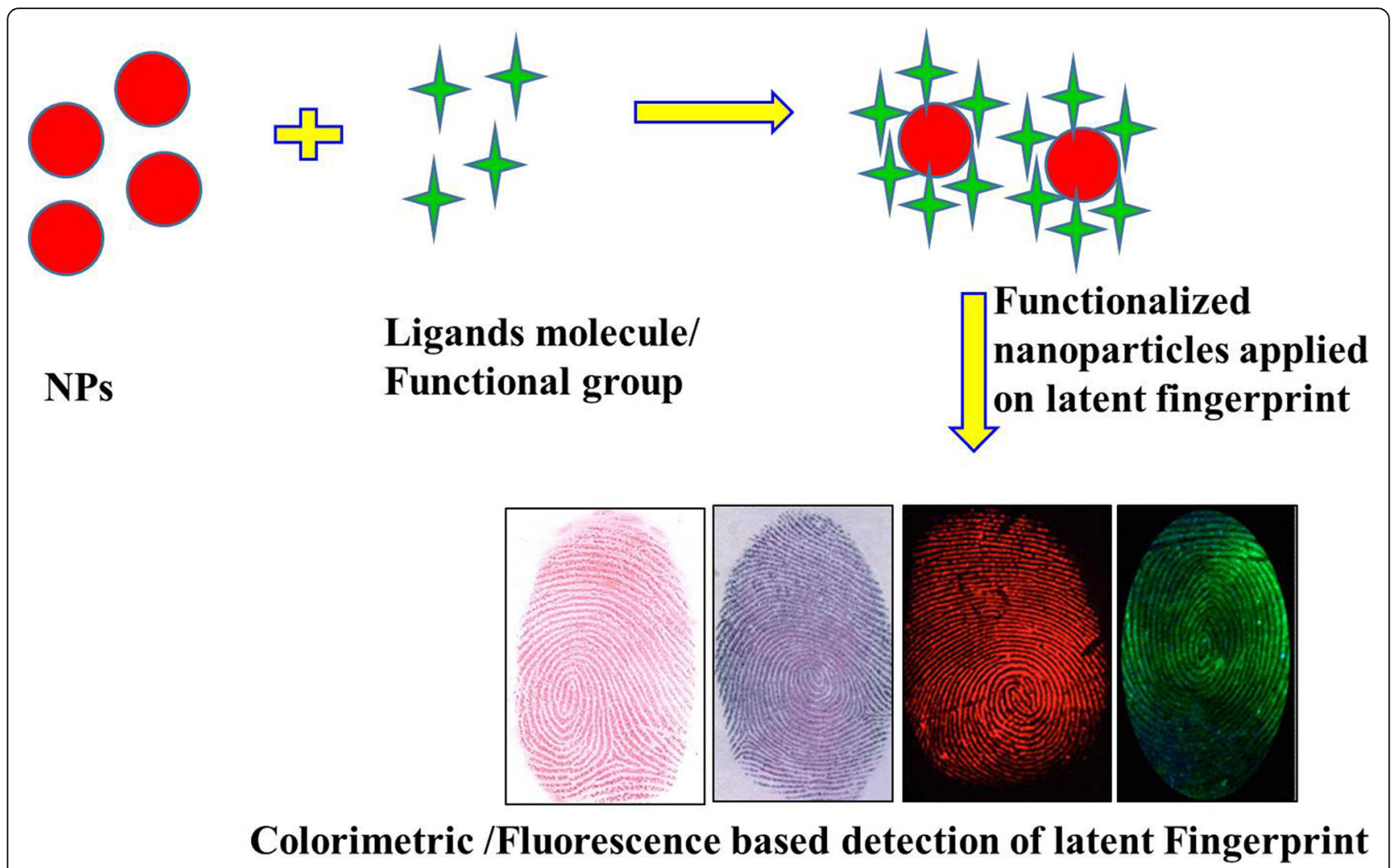

Fig. 2 Latent fingerprint developed on various nonporous/semi-porous surfaces using functionalized nanoparticles

gunshot residue after the crime. High-resolution scanning electron microscope (SEM) imaging can be used to identify gunshot residue while with the combination of X-ray spectrometry, it may helpful to determine the elements that constitute the gunshot residue. The recent study exhibited that gunshot residue analysis is an important step in the shooting cases that can help in prevention of crimes in the society by providing adequate corroborative evidence (Chalmers et al. 2012). However, these procedures are time-consuming, required instruments, and chances of error are more.
Pandya et al. 2012 have revealed that turmeric extracted curcumin nanoparticles-based, highly selective, and ultrasensitive fluorescent probe can be used for the Trinitrotoluene (TNT) detection up to $1 \mathrm{nM}$ level in aqueous solution (Fig. 3). Chu et al. 2015 proposed a novel sensing technique for a label-free and selective detection of 2,4, 6-trinitrotoluene (TNT) from $10^{-12}$ to $10^{-4} \mathrm{M}$ based on amine-terminated nanoparticles. These studies open up a new prospect for rapid, easy, and reliable detection of TNT from environmental samples and also at the crime scenes by measuring the fluorometric intensity.

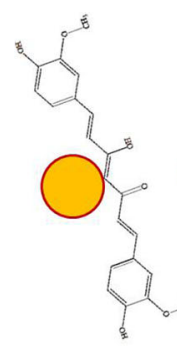

Curcumin NPs

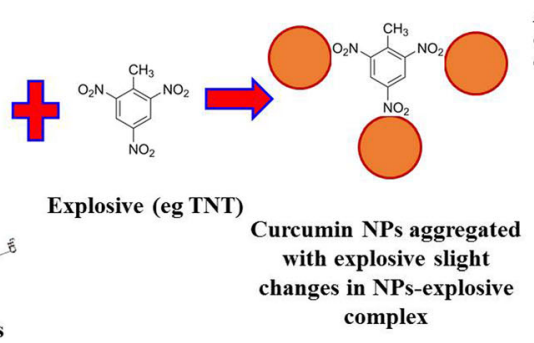

Curcumin NPs aggregated with explosive slight
changes in NPs-explosive complex

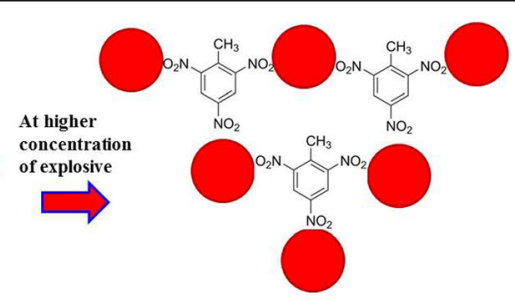

Significant color change observe in NPs-explosive complex

Fig. 3 Application of nanoparticles in explosive detection: schematic representation of interaction between nano-curcumin and TNT 


\section{DNA analysis}

Increasing heinous crime rate is the biggest challenging issue in our modern society. To prevent such crimes and to punish the perpetrators by ensuring them to put behind the bar, nanotechnology can be one of the most vital techniques. Presence of genetic materials is DNA; one of the most important corroborative evidence that helps to identify the presence of the person at the scene of crime whether DNA belongs to victim or perpetrator. Nowadays, magnetic nanoparticles are being used to extract DNA from different biological sources like the blood, hair, skin, semen, and saliva (Castella et al. 2011). In addition, more advancement occur in the field of DNA analysis by developing nanotechnology-based tools that can be used to read DNA sequence in a molecule directly (McCord 2006). Moreover, by putting the DNA molecules on carbon nanotubes, DNA sequence can be analyzed using atomic force microscopy technique (McCord 2006).

\section{Ion beam analysis}

Ion beam analysis is one of the sophisticated instrumental techniques that can be employed to examine forensic materials. This technique can be used to detect, identify, and analyze the residues obtained from gunshots, explosives, soil, ink, and finger prints. This technique can help to establish the link of suspect/suspects with the crime scene and criminal act (McGuire 2012; Meng and Caddy 1997). This method helps to analyze elemental composition of materials which found at the crime scene by comparing it with reference materials. The ion beam analysis is a highly sensitive technique and capable to analyze most of the elements quantitatively as compared to the traditional methods. The ion beam analysis is a modern technique that employs milli electron volts $(\mathrm{meV})$ ion beams to identify the samples composition attained from the scene of crime. Ion beam analysis technique is also used to detect elements in the sub monolayer and its elemental depth profiling. The depth profiling ranges from few nanometers to $10 \mathrm{~nm}$ (Saverio Romolo and Margot 2001).

In ion beam analysis, when beam strikes the surface of sample, charged particle interacts with electrons and nuclei of the atoms of the sample. In this order, particle emission occurs (Shinde et al. 2010). These particle or radiation emissions signify the qualitative as well as quantitative analysis of elements that constitute the sample being examined. The analysis process of this technique employs spectrometric process that helps to identify certain elements in different samples via spectral peak and also determine the concentration of the elements through its optical density (OD) value. This technique also helps to determine the thickness, nature, and position of the elements. There are different ion beam analysis techniques coupled with particle-induced X-ray emission, particle-induced Gamma-ray emission used for qualitative and quantitative analyses of the samples. In this order, investigators have choice of methods for analyzing samples according to the requirement of the case and sample obtained from crime scenes (Vedder and Teeuw 2008).

\section{Nano trackers}

Nowadays, trackers and barcodes are used to combat the crime. Trackers are being used as a preventing tool in the form of secret pattern on the products to avoid people from thieving. Apart from preventing tool, trackers can also be help to track down those items which are stolen or missing. Trackers can also be used for security purposes as they can be used to avert prisoners from absconding. In this case, nano trackers are injected into the prisoners' body which helps to track them if they escape. Nano trackers are also enabling to monitor the convicts after being released. Nano trackers help to track them easily if they are again involved in a crime (Hogard and Ellis 2007).

In addition, barcodes also help to prevent crime (Gooch et al. 2016). Nanotechnology helps in determining the authenticity of the items. Nanotechnology can also be applied in various sectors to prevent them from forged or duplicate products (Gooch et al. 2016). Counterfeiting or duplication of products leads to major economic loss and reputation of the respective companies and their countries. Product authenticity is directly linked to the reliability and reputation of the company; if a customer purchases the forged or duplicate products then reliability of the products and reputation of the company will be gone. If companies fabricated forged products and pass them off as authentic, it may affect both consumers and companies as they suffer losses. Uses of watermarks may help to prevent duplication of products by differentiating genuine from forged products (Gooch et al. 2016). With the help of nanotechnology, various tools are being developed that could be able to differentiate forged products from authentic one. In this way, nanotechnology helps to prevent counterfeit crime. Nano technology has been developed nanofibers and nanodots with diverse colors to detect duplicate products. These nanofibers and nanodots have been detected using various forensic light sources that are meant to decipher the nanofibers and nanodots. So, in this way, counterfeit crime has been prevented (Teeuw et al. 2008).

Additionally, different types of criminal cases like hit and run, burglary, and fraud can also be investigate with the help of nanotechnology (Chalmers et al. 2012). Nanotechnology is also relevant in those cases in which petroleum products are involved such as arson cases to 
examine the petroleum hydrocarbon traces. Furthermore, nanotechnology is also pertinent in the cases related to cyber (mobile and internet) and sting operations (authentication of tapes and identification of speakers). In these cases, the investigators scrutinize suspected tapes by identifying the coating of nanomaterials on its surface which is a marking of authentication.

\section{Screening of drug-facilitated crime}

Drug-facilitated crime (DFC), commonly termed as "date rape" includes rape or other sexual assault, robbery, money extortion, and physical harm to all ages of individual under the influence of psychotropic substances (Nasir Uddin 2014; Zhai et al. 2014; Sanghavi et al. 2014). The intention of this crime is to impair the behavior, perception, or decision-making capacity of the individual under the influence of drug. These impairments may further extend to take unwanted advantages from impaired individual, with or without his/her consent. Thus, detection of illicit drugs is a challenging task for many forensic experts because of its unavailability in original form in the questioned sample which has been sent to the forensic science laboratory for examination. The conventional method of drug testing is allied with various issues such as cost-effectiveness, instrument limitations, and sensitivity; therefore, to evade such issues, application of nanotechnology into the pharmaceutical industry becomes essential for drug analysis. Nanotechnology plays a vital role in detection of illicit drugs because it encompasses unique physico-chemical properties and well-known advantages in terms of selectivity, sensitivity, cost-effectiveness, affordability, and capability of miniaturization and automation (Lad et al. 2016). Recently, a study developed a "smart" system using citrate-stabilized gold nanoparticles (AuNPs) as a probe and smartphone camera as an analysis device for rapid detection and quantification of codeine (COD) sulfate. In this method, camera of smartphone used to detect ultrasensitive colorimetric changes in the probe due to the presence or absence of codeine sulfate allows simple, portable, on-spot, rapid, detection of an illicit drug using nanotechnology (Lodha et al. 2014). Furthermore, similar research group also reported a highly sensitive, selective, and cost-effective method for the detection of trace amounts of clonazepam based on AuNPs in the presence of melamine (Lodha et al. 2013) (Fig. 4).

\section{Estimation of time since death}

In medico-legal investigation, time since death (TSD) estimation is a vital step. A precise estimation of TSD may be helpful to provide the accurate time and cause of death. In the conventional method, there are various parameters through which TSD can be estimated. These parameters included algor mortis, changes in the eye, postmortem hypostasis, rigor mortis, changes in decomposition, stomach and bowels content, contents of urinary bladder, and anecdotal evidences. All of these parameters can only provide approximate time of death. The observational changes in body fluids (blood, pericardial fluid, synovial fluid, spinal fluid, aqueous humor, and vitreous humor) are useful additional procedures to establish TSD, immediately or shortly after death (Garg et al. 2004).Out of these body fluids, vitreous humor $(\mathrm{VH})$ remains unchanged even after a long time span of death. It exhibited that the biochemical changes (level of amino acid) in $\mathrm{VH}$ is slow and therefore, by the help of this biochemical analysis, TSD can be estimated accurately (Swann et al. 2010). Recently, a smart, rapid, sensitive, cost-effective, and lab on chip method have been developed that provides easy determination of cysteine, an amino acid (Fig. 5) (Swann et al. 2010).This method may lead to estimate the TSD up to $96 \mathrm{~h}$ till cystine concentration from $\mathrm{VH}$ increases significantly and showing a linear correlation with expansion of TSD. In the near future, this method can be developing a microfluidic system, smart approach-based detection to estimate the

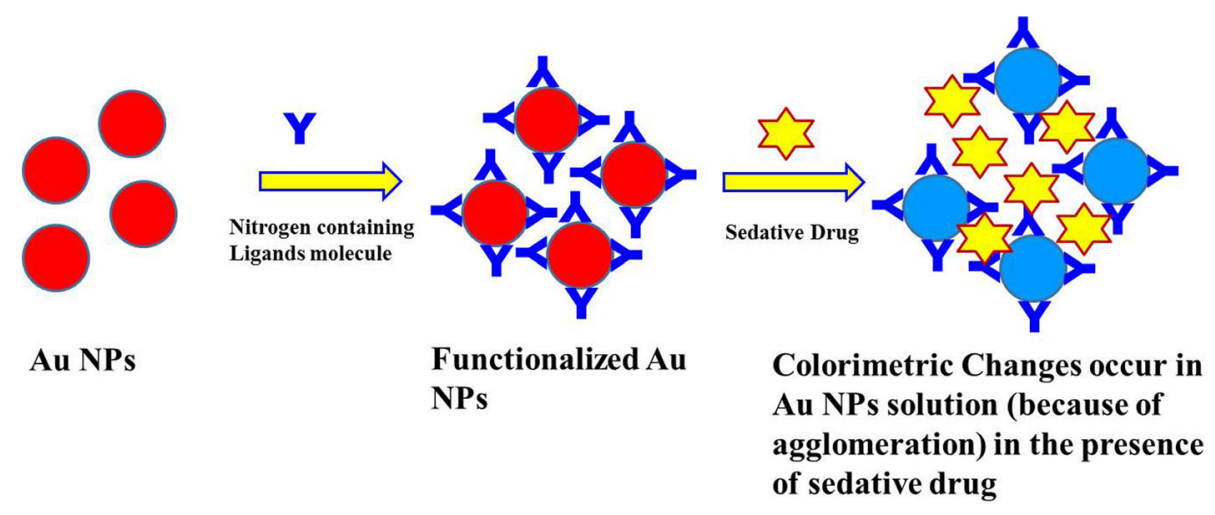

Fig. 4 Application of nanoparticles in sedative drug detection: schematic diagram of gold nanoparticles interaction with clonazepam 


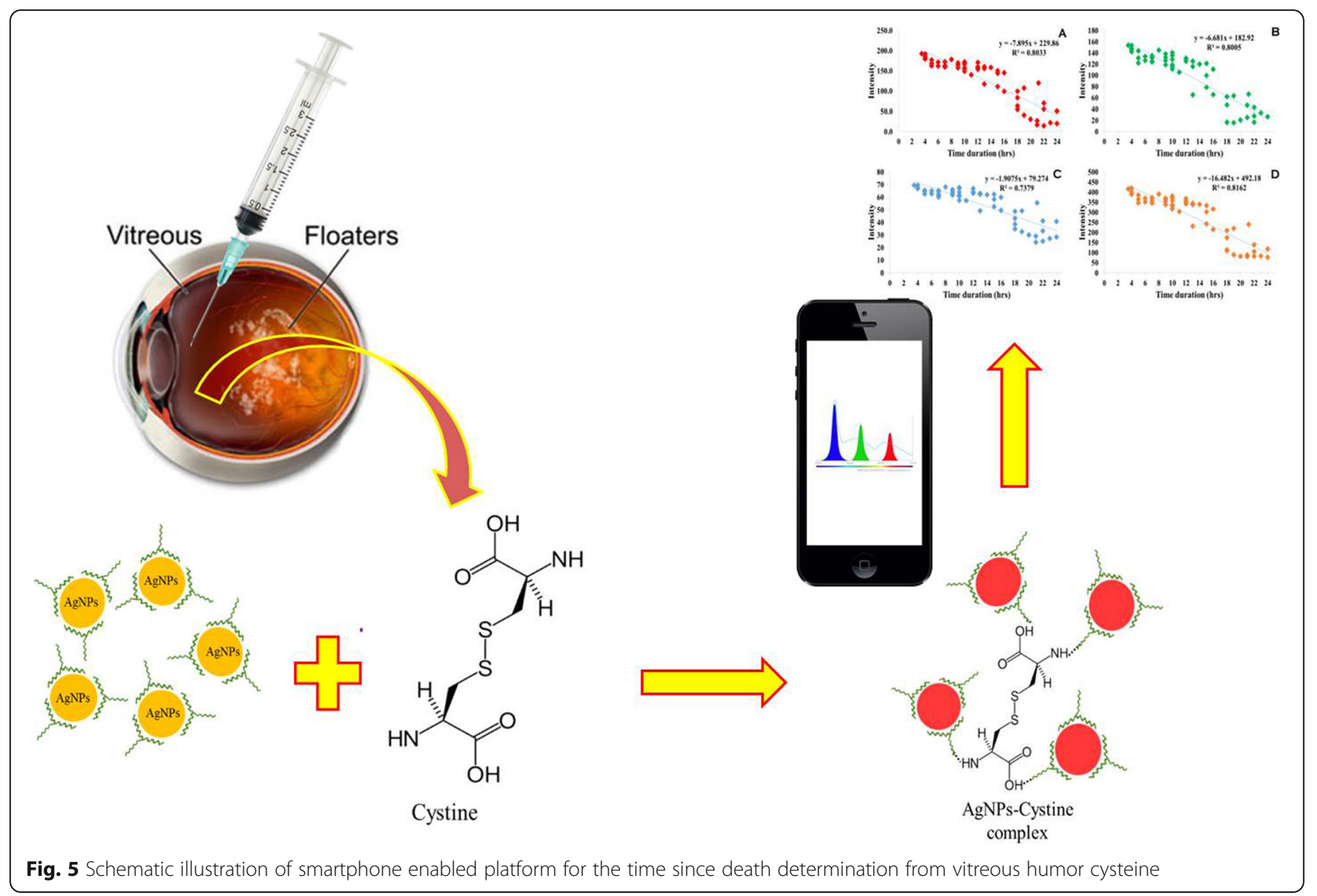

cysteine concentration and correlate it with TSD estimation (Ansari et al. 2016). Recently, Williams and his colleagues have developed a flow cytometry-based method to estimate TSD. In this method, DNA degradation rate of spleen and brain tissues were measured up to $96 \mathrm{~h}$ and brain tissue found more suitable as compared to spleen (Williams et al. 2015). Furthermore, in another study, potential application of flow cytometry for TSD estimation was well elucidated. In this study, flow cytometry-based method was able to detect erythrocytes in contaminated VH. This method helped in screening of samples for which the biochemical results would not be consistent. Due to higher sensitivity of flow cytometry as compared to conventional method, nowadays this screening test becomes the most popular method for the estimation of TSD (Cordeiro et al. 2015). This flow cytometry-based method would give a pace to legal medicine and help to avoid the false interpretation and reduce the number of pending cases in the court (Cordeiro et al. 2015; Shukla 2016). In the near future, amino acid concentration from $\mathrm{VH}$ can be detected by fluorescent nanoparticles and then quantification could be assessed using flow cytometry which would be a possible approach to estimate TSD precisely.

\section{Security}

Nanotechnologies in the forensic science and security can modernize the approach an investigation is executed by reducing time, cost and expertise required, and simultaneously increasing precision and accessibility of nano collection and analysis devices (Fig. 6) (Shukla 2016). Since nanotechnology is a branch of applied science in its initial stages of development, many of the drifts and application strategies are still anticipated but not yet fully established to work. General apprehensions regarding nanotechnology differ from the lack of cohesive terminology; the health and safety concerns widely reflected about application of nanotechnology in everyday life; to the "balance of power in the world" which may be exposed by the possible "nanomaterials," and many others (Litton 2008). However, in linking with the security domain further, social, ethical, and legal disputes may be explored. In India, lack of awareness about the security sector is the major social concerns. This gap can be filled by conducting more and more awareness program at each and every level through which people get aware about security sector and access their data with full security. But, it definite leads to the compulsion of specific legislation to prevent unlawful access or 


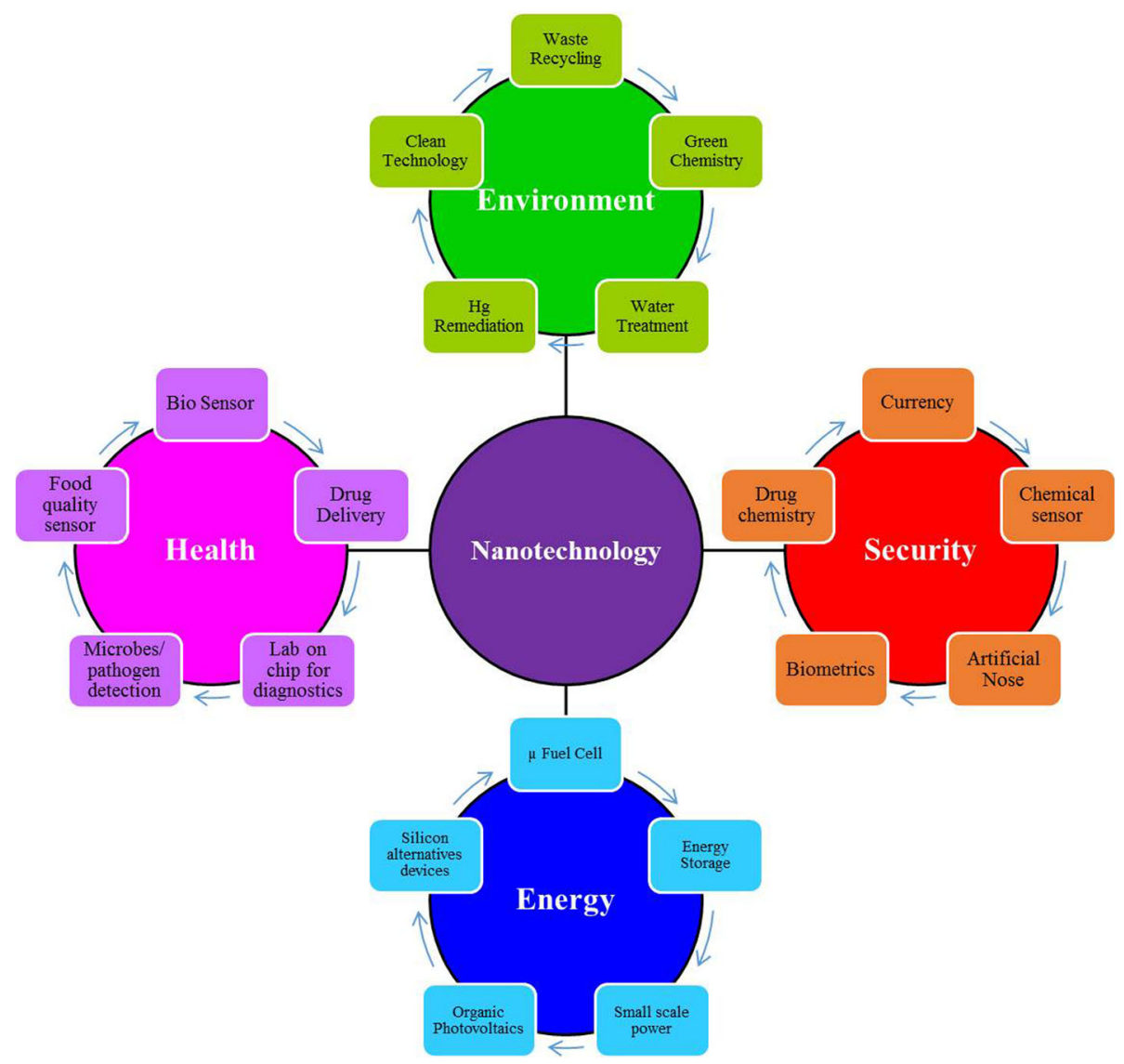

Fig. 6 Application of nanotechnology in various sectors

disappearance. Additionally, the power transfer from government to private parties who retain the knowledge and skills to design the technology used may ask the question about the regulation and quality control of implementation of legal norms by technology, which can be more difficult by the increasing complexity of nanotechnologies.

Furthermore, when nanotechnology comes, some of the most quoted ethical and legal issues are raised. The reason behind that nanotechnology will enable to develop small and hidden devices that can be used to gather and spread secret information about individuals or firm to their rival. Surveillance devices would be able to conquer people's privacy, but the nanodevices are small and eventually extensively available, allowing not only government but also private parties to access sensitive personal information (Stankova 2015).

Accountability is another major issue being discussed, since human behavior may influence and controlled by nanotechnologies, and when the behaviors are externally controlled, it might be hard to prove the intent of the act. Additionally, individual's liberty can be probed, when we will have dealt with many non-essential information and alternatives.
Further queries about acceptability of the technology and its development would invade the conventionally running system like government administration, and law and order (Katrina 2008). Katrina explained about the integration of nanotechnology with the neuroscience. She emphasized that nanotechnology may affect the commonsense psychology by providing new information about the mental states (alteration, inhibition or implanting) from the suspected person which are relevant for the case investigation process. Herein, nanotechnology helps to make the common sense psychology process more informative, and if this integration is executed precisely, then the injustice seems to be tougher to escape from else.

Finally, any kind of technology advancement has always been carried out inherent jeopardies and in majority of cases benefits have balanced the adverse effect. This may also happen with nanotechnologies, which provide such an extensive range of revolutionary prospects for protection of security (Simonis 2006). These altogether will indeed augment both theoretical and applied prospect of science. From the legal and ethical point of view, extenuation of risks can be found in the conception of pertinent 
regulation that reflects all identified issues together with stringent control on the advancement of design, so that no unnecessary norms are imposed through it.

\section{Future aspects}

This review can indicate the exposure of this new area of research to solve the crime on site with the help of nanotechnology. The potential integration of all laboratory processes onto a nanoplatform is conceivably the most interesting development which may further minimize laboratory contamination issues. Advanced developments in nanotechnology tools like nanoprobes, nanodevices, and nanochips can be effective approaches to prevent crime and provide augmenting security to the society. Nanotechnology can be helpful to protect people from varied range of criminal activities like violent crimes, rape, murder, theft, fraud, and terrorist attacks. It can also be used to shield kids, teenagers, and elders from kidnapping, cybercrime, and abduction. Since the past decades, the crime rate has increased enormously in the society and weak execution of crime prevention and investigation approaches are the two major confounding factors to enhance it. Most of the conventional methods employed to prevent crime are not effective. These traditional methods require proper collection and preservation of the evidence and takes time to reach at laboratory where analyses are also taking ample of time. These will not only increase the number of pending cases in the court but also their reliability and credibility in the court is also an important issue.

Nanoplatform can help to improve the evidence analysis procedure (detection, collection, and preservation of evidence) obtained from the crime scene; provide pace in investigation process. Nanodevices can be employed to analyze residual evidences obtained from variety of cases like bomb explosion, gunshots, hit and run, sexual assault, arson, cybercrime, and burglary. Residual analysis and its elemental composition can be assessed by most sensitive ion beam analysis method. Moreover, forensic workforce must be equipped with nano-based handheld small devices/techniques that help to analyze the evidence on the spot at the scene of crime which may provide a pace in investigation process. In the conventional approach of investigation, experts took blood, semen, fingerprint, hair, and other types of evidences at the crime scene, collect and preserved it, and by the time send it to the laboratory for examination. Development of multifunctional nanodevice as handheld mini-lab at the crime scene can help to analyze the evidence on the field that would save the time of evidence collection and examination.

Certain nanomaterials like carbon, gold, and silver are preferably applied for the preparation of chemically modified electrodes for drug sensing. However, nanoparticles made from platinum, palladium, or metal oxides have not been used vastly for this purpose. The use of nanoparticles as modifiers is anticipated to be a matter of great research interest in the field of nanomaterial-based devices for detecting illicit drugs.

The future may also embraces many possibilities for nanomaterial-based devices available for the detection and investigation of crime, surveillance, and tracking the missing or stolen items. Nanomaterial-based devices may also be available for differently abled individuals that require the assistance of others to track their whereabouts. Adaptation of new nanomaterial-based devices by our law enforcement agencies and officers to combat the crime would shape our future. Prior to adopting these technologies, agencies must know what technology will be available and should also know how they will acquire it to protect their society. Our future would have possibilities to develop a safer and crime-free environment through the use of nanotechnology. Our responsibility in this regard is to set standards and protocols for the ethical norms of this emerging technology, produce skilled persons to handle these techniques, and constantly improve our strategies to combat and prevent the crime in the society.

\section{Conclusion}

The question still remains whether law enforcement agencies and officers are ready to acquire and apply this nano-based technology and devices for factual science or it remains in science fiction and research purposes only. It is reassuring to know that potential of nanotechnology can make a positive social contribution and it would not only help to solve the crime but also prevent the crime. In the near future, nanotechnology may assist as an innovative and preventive tool in the various field of forensic science like virtual autopsy, crime scene investigation, fingerprint identification, questioned document, ballistics, and toxicology.

\section{Abbreviations}

AuNPs: Gold nanoparticles; COD: Codeine; DFC: Drug-facilitated crime; OD: Optical density; SEM: Scanning electron microscope; TNT: Trinitrotoluene; TSD: Time since death; VH: Vitreous humor

\section{Acknowledgements}

RKS gratefully acknowledged the Science and Engineering Research Board (SERB), Department of Science and Technology, Government of India for providing grant under Early Career Research Award (ECR/2016/001310) scheme. AP gratefully acknowledges the funding from SERB, India under Young Scientist Start-up Grant (YSS/2015/000258).

\section{Funding}

Science and Engineering Research Board (SERB), Department of Science and Technology, Government of India Project grant (ECR/2016/001310) received by Ritesh K Shukla.

Science and Engineering Research Board (SERB), Department of Science and Technology, Government of India Project grant (YSS/2015/000258) received by Alok Pandya. 


\section{Authors' contributions}

All designing and text of the review are jointly written by AP and RKS, and formatting and figures are done by RKS. Both authors read and approved the final manuscript.

\section{Ethics approval and consent to participate} Not applicable.

\section{Consent for publication}

This manuscript has not been submitted for publication nor has it been published in whole or in part elsewhere. We confirm that this manuscript has been read and approved by both of us.

\section{Competing interests}

This manuscript is not providing any direct or indirect financial benefit or loss to any organization including mine. This review is based on existing knowledge, and not any text content has been taken from any holding or currently applying for patents. Figures have already been modified.

\section{Publisher's Note}

Springer Nature remains neutral with regard to jurisdictional claims in published maps and institutional affiliations.

\section{Author details}

${ }^{1}$ Center for Engineering and Enterprise, Institute of Advanced Research, Gandhinagar 382426, Gujarat, India. ${ }^{2}$ Biological and Life Sciences, School of Arts and Sciences, Ahmedabad University, Central Campus, Navrangpura, Ahmedabad 380009, Gujarat, India.

Received: 18 May 2018 Accepted: 17 September 2018

Published online: 28 September 2018

\section{References}

Ansari N, Lodha A, Menon S (2016) Smart platform for the time since death determination from vitreous humor cystine. Biosens Bioelectron 86:115-121

Arshad A, Farrukh M, Ali S, Khaleeq-ur-Rahman M, Tahir M (2015) Development of latent fingermarks on various surfaces using $\mathrm{ZnO}-\mathrm{SiO} 2$ nanopowder. J Fore Sci 60:1182-1187

Castella V, Kummer D, Gehrig C, Hall D (2011) DNA extraction using the QI asymphony: evaluation of PCR inhibitor removal. Fore Sci Int Genet Supplement Series 3:e69-e70

Chalmers J, Edwards H, Hargreaves M (eds) (2012) Infrared and Raman spectroscopy in forensic science. Wiley, Singapore

Chen Y (2011) Forensic applications of nanotechnology. J Chin Chem Soc 58:828-835

Colton R (2003) Counterterrorism: making the world a safer place. Sci 299: 1324-1325

Cordeiro C, Seoane R, Camba A, Lendoiro E, Rodríguez-Calvo M, Vieira D et al (2015) The application of flow cytometry as a rapid and sensitive screening method to detect contamination of vitreous humor samples and avoid miscalculation of the postmortem interval. J Fore Sci 60:1346-1349

Docobo J (2005) Community policing as the primary prevention strategy for homeland security at the local law enforcement level. Homeland Secur Aff 1: 4 (June 2005). https://www.hsaj.org/articles/183

Foquet M, Korlach J, Zipfel W, Webb WW, Craighead HG (2002) DNA fragment sizing by single molecule detection in sub-micrometer-sized closed fluidic channels. Anal Chem 74(6):1415-1422

Garg V, Oberoi SS, Gorea RK, Kaur K (2004) Changes in the levels of vitreous potassium with increasing time since death. J Ind Acad Fore Med 26(4): 136-139

Giannoukos S, Brkić B, Taylor S, Marshall A, Verbeck GF (2016) Chemical sniffing instrumentation for security applications. Chem Rev 116(14):8146-8172

Gooch J, Goh H, Daniel B, Abbate V, Frascione N (2016) Monitoring criminal activity through invisible fluorescent "peptide coding" taggants. Anal Chem 88(8):4456-4460. https://researcharchive.vuw.ac.nz/xmlui/bitstream/handle/ 10063/1820/thesis.pdf? sequence $=1$

Gordon MF (2011) Working on crime: individual and team management of knowledge for decision making in the initial investigative process. Dissertation, Victoria University of Wellington

Hogard E, Ellis R (2007) Community safety. Innovation and Evaluation, Chester, UK: Chester Academic Press;
Katrina S (2008) Nanotechnology and the attribution of responsibility. Nanotechnol Law Bus 5:2 https://papers.ssrn.com/sol3/papers.cfm?abstract_ id $=1127279$

Kosal M (2008) Bioviolence: preventing biological terror and crime - by Barry Kellman. Rev Pol Res 25:492-495

Lad N, Kumar A, Pandya A, Agrawal YK (2016) Overview of nano-enabled screening of drug-facilitated crime: a promising tool in forensic investigation. Trends Anal Chem 80:458-470

Litton P (2008) "Nanoethics'? What's New? Hastings Center Report, 37, Available at SSRN: https://papers.ssrn.com/sol3/papers.cfm?abstract_id=1311533

Lodha A, Pandya A, Shukla RK (2016) Nanotechnology: an applied and robust approach for forensic investigation. Fore Res Crim Int J 2(1):1-4

Lodha A, Pandya A, Sutariya P, Menon S (2013) Melamine modified gold nanoprobe for "on-spot" colorimetric recognition of clonazepam from biological specimens. Anal 138:5411-5416

Lodha A, Pandya A, Sutariya P, Menon S (2014) A smart and rapid colorimetric method for the detection of codeine sulphate, using unmodified gold nanoprobe. RSC Adv 4:50443-50448

Mark D, Haeberle S, Roth G, von Stetten F, Zengerle R (2010) Microfluidic lab-ona-chip platforms: requirements, characteristics and applications. Chem Soc Rev 39:1153-1182

McCord B (2006) Nanotechnology and its potential forensic DNA analysis. Profiles in DNA. International forensic research institute, pp 7-9. https:// www.promega.in/resources/profiles-in-dna/2006/nanotechnology-and-itspotential-in-forensic-dnaanalysis/

McGuire MR (2012) Technology, Crime and Justice: The Question Concerning Technomia. Routledge 226 ISBN 9781843928577, Routledge, Teylor \& Francis Group

Meng H, Caddy B (1997) Gunshot residue analysis—a review. J Fore Sci 42:14167J

Menzel E (2001) Recent advances in photoluminescence detection of fingerprints. The Scientific World J 1:498-509

Mosher PV, McVicar MJ, Randall ED, Sild EH (1998) Gunshot residue J Cana Soc Fore Sci 31(3):157-168

Nasir Uddin M (2014) An overview on total analytical methods for the detection of 1,4-benzodiazepines. Pharm Anal Act 5:303

Pandya A, Goswami H, Lodha A, Menon S (2012) A novel nanoaggregation detection technique of TNT using selective and ultrasensitive nanocurcumin as a probe. Anal 137:1771

Pitkethly M (2010) Nanotechnology and forensics, mat. Today 12(6). Retrieved from: https://www.materialstoday.com/nanomaterials/articles/s1369702109701671/

Saiyed ZM, Ramchand CN, Telang SD (2008) Isolation of genomic DNA using magnetic nanoparticles as a solid-phase support. J Phys 20(20):204153

Sanghavi B, Wolfbeis O, Hirsch T, Swami N (2014) Nanomaterial-based electrochemical sensing of neurological drugs and neurotransmitters. Micro chem Act 182:1-41

Saverio Romolo F, Margot P (2001) Identification of gunshot residue: a critical review. Fore Sci Int 119:195-211

Shinde SA, Malve MK, Prabha C, Garad MV (2010) Nanotechnology and forensic science. Nanotech and Nano Sci 1(1):19-21

Shukla RK (2013) Occupational exposure of nanoparticles in forensic science: a need of safe use. Int J Fore Sci Pathol 1(3):7-10

Shukla RK (2016) Forensic biotechnology: application of flow cytometry in legal medicine. Int J Fore Sci 1(1):1-2

Simonis F (2006) Nanotechnology for security, http://www.futuretechnologycenter.eu/ downloads/nanobook.pdf

Stankova D (2015) Application of Nanotechnology In Security, http://elaw.guide/ application-nanotechnology-security/

Su B (2016) Recent progress on fingerprint visualization and analysis by imaging ridge residue components. Anal Bioanal Chem 408:2781-2791

Swann L, Forbes S, Lewis S (2010) Analytical separations of mammalian decomposition products for forensic science: a review. Anal Chem Act 682:9-22

Teeuw WB, Vedder AH, Custers BHM, Dorbeck-Jung BR, Faber ECC, lacob SM, Koops BJ, Leenes RE, de Poot HJG, Rip A, Vudisa JN (eds) (2008) Security applications for converging technologies, impact on the constitutional state and the legal order. Boom Juridische Uitgevers, Den Haag

Torgal FP, Jalali S (2011) Eco-efficient construction and building materials Springer, p 226

Vedder A, Teeuw W (2008) Security application for converging technologies. ISBN 978905454826 3, The Hague, the Netharland Boom Juridische Uitgevers, pp 1-226 
Williams T, Soni S, White J, Can G, Javan G (2015) Evaluation of DNA degradation using flow cytometry. Amer J fore Med and Path 36:104-110

Worley C, Wiltshire S, Miller T, Havrilla G, Majidi V (2006) Detection of visible and latent fingerprints using micro-X-ray fluorescence elemental Imaging J. Fore Sci 51:57-63

Zhai D, Tan Y, Xu W, Chang Y (2014) Development of a fluorescent sensor for illicit date rape drug GHB. Chem Comm 50:2904

Submit your manuscript to a SpringerOpen ${ }^{\circ}$ journal and benefit from:

- Convenient online submission

- Rigorous peer review

- Open access: articles freely available online

High visibility within the field

- Retaining the copyright to your article

Submit your next manuscript at $\boldsymbol{\sim}$ springeropen.com 